\title{
ACUTE TOXICITY EVALUATION OF PROTODIOSCIN RICH EXTRACT OF TRIGONELLA FOENUM-GRAECUM L IN RATS
}

\author{
KETAN VARIYA, SANDIP PATEL, VIJAYKUMAR PARMAR*
}

Department of Pharmaceutical Chemistry, Analysis and Quality Assurance, Ramanbhai Patel College of Pharmacy, Charotar University of Science and Technology, CHARUSAT Campus, Changa, Petlad, Anand, Gujarat, India. Email: vijayparmar.ph@charusat.ac.in

Received: 15 August 2014, Revised and Accepted: 31 August 2014

\section{ABSTRACT}

Objectives: The objective of this study was to investigate the acute toxicity of standardized protodioscin rich extract (PRE) of Trigonella foenumgraecum L (26.63\% w/w; PRE).

Methods: To evaluate the toxicity of PRE, the acute toxicity of the extract on adult rats were investigated. A fixed large dose of 2 g/kg body weight of PRE was administrated by a single oral gavage, and $1 \mathrm{~g} / \mathrm{kg}$ body weight of PRE was administered by intravenous according to the Organisation for Economic Co-operation and Development guidelines.

Results: In 2 weeks, PRE showed no obvious acute toxicity. There were no deaths in either group and no change in the clinical signs. The hematological and biochemical analyses showed some changes that returned to reference levels without impairment of homeostasis. The treatment did not induce untoward changes in organs as shown by histological studies. The in vivo results showed that has low toxicity.

Conclusion: PRE is safe and can be potentially used as an aphrodisiac in future studies.

Keywords: Protodioscin, Aphrodisiac, Trigonella foenum-graecum, Organisation for Economic Co-operation and Development, Toxicity, Histopathological studies.

(C) 2016 The Authors. Published by Innovare Academic Sciences Pvt Ltd. This is an open access article under the CC BY license (http://creativecommons. org/licenses/by/4. 0/) DOI: http://dx.doi.org/10.22159/ajpcr.2016.v9s3.14706

\section{INTRODUCTION}

Traditional medicine is one of the most accessible tools to satisfy people's healthcare need. However, limited studies on traditional medicinal plants hinder utilization of plant-based medicine. Therefore, to develop safe natural plant products, preliminary studies are necessary to evaluate possible risks such as undesirable side effects and to determine appropriate dosage levels and regimens to avoid overdosing or poisoning of patients [1].

Trigonella foenum-graecum L. (Fabaceae), popularly known as fenugreek, is an aromatic $30-60 \mathrm{~cm}$ tall annual herb, originating in India and Northern Africa and cultivated throughout China and India [2]. In traditional Chinese medicine, seeds are used as a tonic and to relieve edema of the legs. In India, it is commonly consumed as a condiment. It is used in indigestion, arthritis, spondylosis, baldness, diabetes mellitus, and hyperlipidemia [3-6]. It is also used as appetizer and galactogogues [2,7] The seeds of T. foenum-graecum are used in the ayurvedic formulations Mustakarista and Mrtasanjivni Sura [8]. T. foenum-graecum seeds contain several bioactive constituents, viz., amino acid 4-hydroxy isoleucine, steroidal saponin - trigoneoside, trigofoenosides, protodioscin protogracillin, diosgenin, alkaloid trigonelline, flavonoids, and mucilage [9]. Protodioscin, 26-0- $\beta$-d-glycopyranosyl-22-hydroxyfurost-5 ene-3 $\beta$, 26-diol-3-0- $\beta$-diglucorhamnoside, belongs to the furostanol class of saponin, having a molecular weight $1049.2 \mathrm{~g} \mathrm{~mole}^{-1}$. It is freely soluble in water, sparingly soluble in methanol, and insoluble in chloroform and ethyl acetate. Protodioscin is claimed to have aphrodisiac activity [10-18] due to its ability to enhance testosterone levels in the body [19]. Protodioscin is also reported to have anticancer activity [20].

However, there is no reported acute toxicity for protodioscin rich extract (PRE). Thus, it is necessary to evaluate the safety and toxicity of PRE to establish clinical safety and a premise for pharmacodynamic studies. The present study provides data on the safety of PRE by examining the acute toxicity of orally administered PRE to SpragueDawley rats.

\section{METHODS}

Preparation of standardized PRE of T. foenum-graecum T. foenum-graecum powder $(200 \mathrm{~g})$ was defatted by hot reflux on water bath using hexane $(3 \times 500 \mathrm{ml})$ for $4 \mathrm{hrs}$. The defatted material was subjected to hot reflux extraction on water bath using $20 \%$ methanol $(3 \times 700 \mathrm{ml})$ for $3 \mathrm{hrs}$. Methanol was used for denaturation of glycosidase enzymes which are responsible for the breakdown of the glycosides. The pooled extract was filtered, concentrated under reduced pressure, and then partitioned with chloroform $(4 \times 500 \mathrm{ml})$. Chloroform layer was discarded, and aqueous part was partitioned with ethyl acetate $(3 \times 500 \mathrm{ml})$. Ethyl acetate layer discarded and the aqueous layer was partitioned with $\mathrm{n}$-butanol $(3 \times 400 \mathrm{ml})$. N-butanol fraction was evaporated in rotary flask evaporator to get the solid residue (Yield-8\% w/w). Thus, prepared butanolic fraction was analyzed for the protodioscin content using developed HPTLC method [21]. The protodioscin content was found to be $26.63 \% \mathrm{w} / \mathrm{w}$.

\section{Animals}

Wistar albino rats of either sex of 6-12 months age, weighting 250-300 g, were procured from the Animal Vaccines Institute, Gandhinagar. The animals were housed in polypropylene cages with stainless steel grill tops and provided with bedding of clean paddy husk. The animals were acclimatized to laboratory conditions for 1 -week before treatment. All animals were maintained at a controlled temperature $\left[22 \pm 2^{\circ} \mathrm{C}\right]$ under 12 -hrs light/dark cycles and were allowed free access to food and water. The protocol of the study was approved by the Institutional Ethics Committee of the Ramanbhai Patel College of Pharmacy (RPCP/IAEC/2013-2014/R-31r).

\section{Acute toxicity}

All rats of either sex were fasted overnight before treatment and were given food $1 \mathrm{hr}$ after treatment. The hypothesis was made that PRE would be relatively safe because traditional healers use it for the treatment of various ailments. Thus, a single high dose, as recommended by the Organisation for Economic Co-operation and Development 
guidelines [22] of $2.000 \mathrm{mg} / \mathrm{kg}$ and $1000 \mathrm{mg} / \mathrm{kg}$ of PRE dissolved in water for injection was injected via tail vein to 3 rats and administered per oral to 3 rats, respectively.

The animals were observed, and data were recorded at before treatment and 14 days after treatment. The visual observations evaluated changes in the skin, fur, eyes, and respiration, in addition to behavior. Blood (About $1 \mathrm{ml}$ ) was collected (on Day-0 and Day-14) from Retro-orbital plexus of the rat in a micro-centrifuge tube containing disodium EDTA as an anticoagulant. It was assessed for various hematological parameters such as total red blood cells; white blood cells count using Neubauer chamber. Blood (About $2 \mathrm{ml}$ ) was collected (on Day- 0 and Day-14) and allowed to coagulate to get serum. The serum levels of various biochemical parameters were assessed using span diagnostic kits at the institute. The animals then sacrificed, and the organs (liver, heart, kidney, Lung, spleen, and brain) were dissected, and the gross histology of the organs was performed.

\section{Statistical analysis}

The data were analyzed using one-way analysis of variance with Bonferroni post-hoc tests for multiple comparisons using GraphPad Prism (Version 19.0, IBM Corporation, New York, NY, USA). p $<0.05$ was considered statistically significant. Results are expressed as mean \pm standard error mean.

\section{RESULTS AND DISCUSSION}

In general, the knowledge of adverse reactions and side effects of traditional medicines is gained from the experience of administering these medicines. Owing to the limitations of current assessment methods and techniques, little is known about the toxicity of traditional medicines. To ensure their safe use, it is crucial to assess the safety of traditional medicines. In this study, the fixed-dose procedure was used to examine the toxicity of PRE of T. foenum-graecum. After the oral and intravenous administration of PRE, the behavioral responses, mortality, hematological, biochemical, and histopathological examinations were carried out

No significant toxic signs or death was observed during the 14-day observation period. None of the rats showed clinical toxic signs such as anorexia, depression, lethargy, jaundice, and dermatitis and also no mortality happened throughout the examination. Table 1 shows the changes of biochemical parameters in the sera of rats induced by T. foenum-graecum L. PRE after oral and intravenous administration. No significant $(p>0.05)$ variations in parameters were noted between groups, and the levels for all blood chemistry parameters were within the normal range $[23,24]$. The hematological status for rats 14 days after an acute oral administration of the PRE is shown in Table 2. The change was insignificant and, importantly, remained within the normal range.

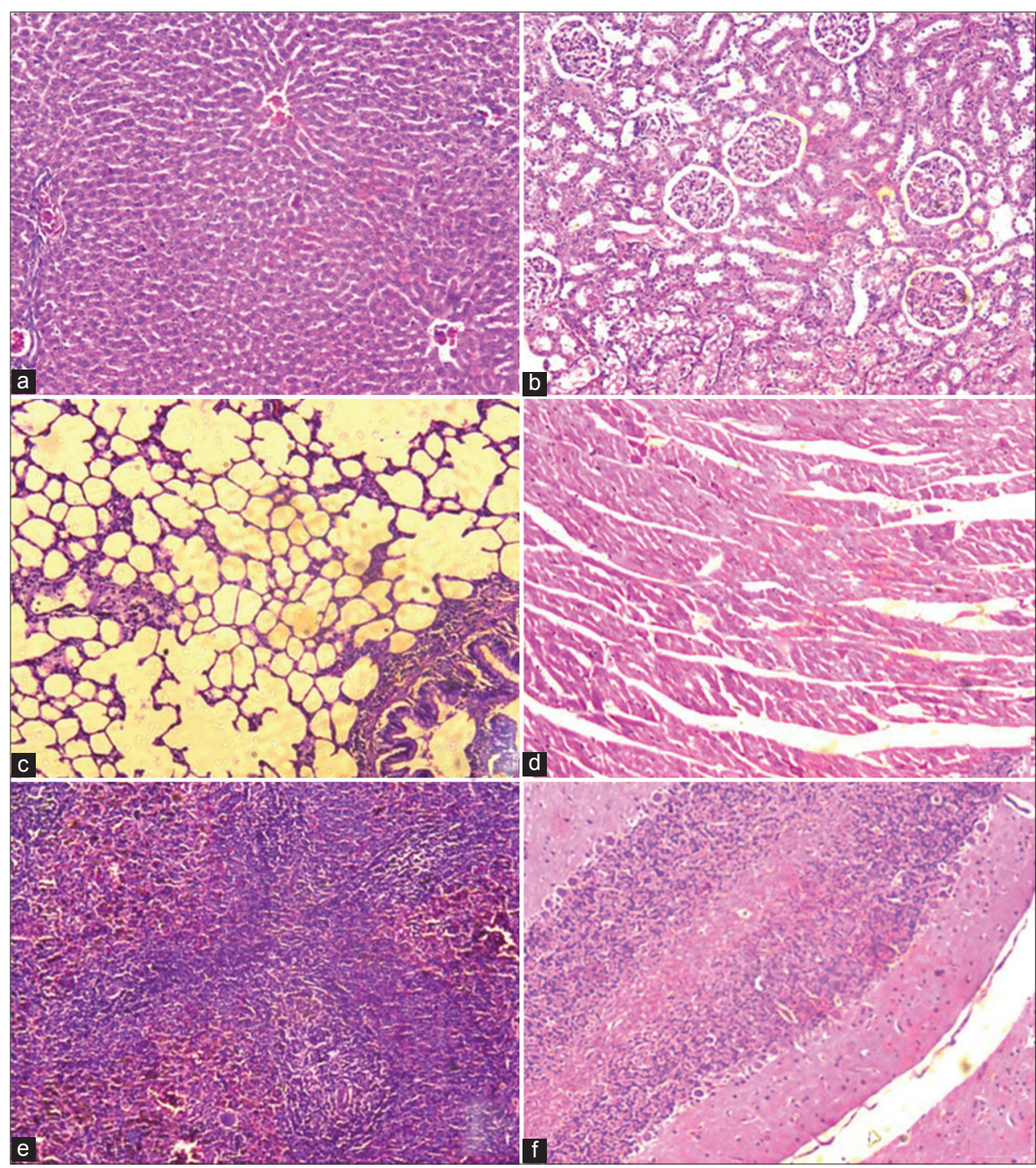

Fig. 1: Histopathological examination of liver (a), kidney (b), lung (c), heart (d), spleen (e), and brain (f) after administration of protodioscin rich extract $(2000 \mathrm{mg} / \mathrm{kg}$; per oral $)$ 
Table 1: Clinical biochemistry values for rats after oral and parenteral administration of protodioscin rich extract of Trigonella foenum-graecum L (Data are expressed as Mean $\pm \mathrm{SEM}$ )

\begin{tabular}{|c|c|c|c|c|c|}
\hline \multirow[t]{2}{*}{ Parameters } & \multirow[t]{2}{*}{ Normal range } & \multicolumn{2}{|c|}{ Oral administration $(n=3)$} & \multicolumn{2}{|c|}{ Parenteral administration $(n=3)$} \\
\hline & & Day 0 & Day 14 & Day 0 & Day 14 \\
\hline Glucose (mg/dL) & $63-165$ & $73.79 \pm 1.55$ & $76.83 \pm 3.88$ & $72.45 \pm 1.277$ & $78.04 \pm 1.174$ \\
\hline AST (IU/L) & $65-203$ & $102.544 \pm 8.9$ & $76.005 \pm 6.47$ & $102.879 \pm 9.59$ & $89.579 \pm 3.12$ \\
\hline $\operatorname{ALT}(\mathrm{mg} / \mathrm{dL})$ & $16-48$ & $41.659 \pm 2.18$ & $30.645 \pm 3.12$ & $45.387 \pm 3.473$ & $36.741 \pm 4.4$ \\
\hline Total protein $(\mathrm{g} / \mathrm{dL})$ & $5.5-7.7$ & $6.563 \pm 0.076$ & $8.017 \pm 0.882$ & $6.378 \pm 0.127$ & $5.762 \pm 0.557$ \\
\hline Albumin $(\mathrm{g} / \mathrm{dL})$ & 3.6-5.5 & $5.328 \pm 0.173$ & $4.948 \pm 0.128$ & $5.254 \pm 0.168$ & $4.772 \pm 0.123$ \\
\hline Bilirubin (mg/dL) & $0.03-0.06$ & $0.053 \pm 0.00$ & $0.051 \pm 0.001$ & $0.052 \pm 0$ & $0.060 \pm 0.09$ \\
\hline Urea $(\mathrm{mg} / \mathrm{dL})$ & $12.3-24.6$ & $17.91 \pm 2.33$ & $20.37 \pm 1.86$ & $16.90 \pm 3.26$ & $19.63 \pm 3.246$ \\
\hline Uric acid (mg/dL) & $4.7-6.7$ & $5.4 \pm 0.77$ & $4.5 \pm 0.235$ & $4.7 \pm 0.819$ & $5.2 \pm 0.480$ \\
\hline Creatinine $(\mathrm{mg} / \mathrm{dL})$ & $0.2-0.6$ & $0.63 \pm 0.088$ & $0.63 \pm 0.033$ & $0.35 \pm 0.035$ & $0.46 \pm 0.103$ \\
\hline Blood urea nitrogen $(\mathrm{mg} / \mathrm{dL})$ & $15-21$ & $22.07 \pm 1.507$ & $17.77 \pm 0.38$ & $19.03 \pm 2.484$ & $15.68 \pm 0.447$ \\
\hline Cholesterol (mg/dL) & $23-97$ & $71.91 \pm 2.902$ & $36.71 \pm 3.08$ & $70.92 \pm 3.443$ & $64.79 \pm 5.03$ \\
\hline
\end{tabular}

SEM: Standard error mean, T. foenum-graecum: Trigonella foenum-graecum

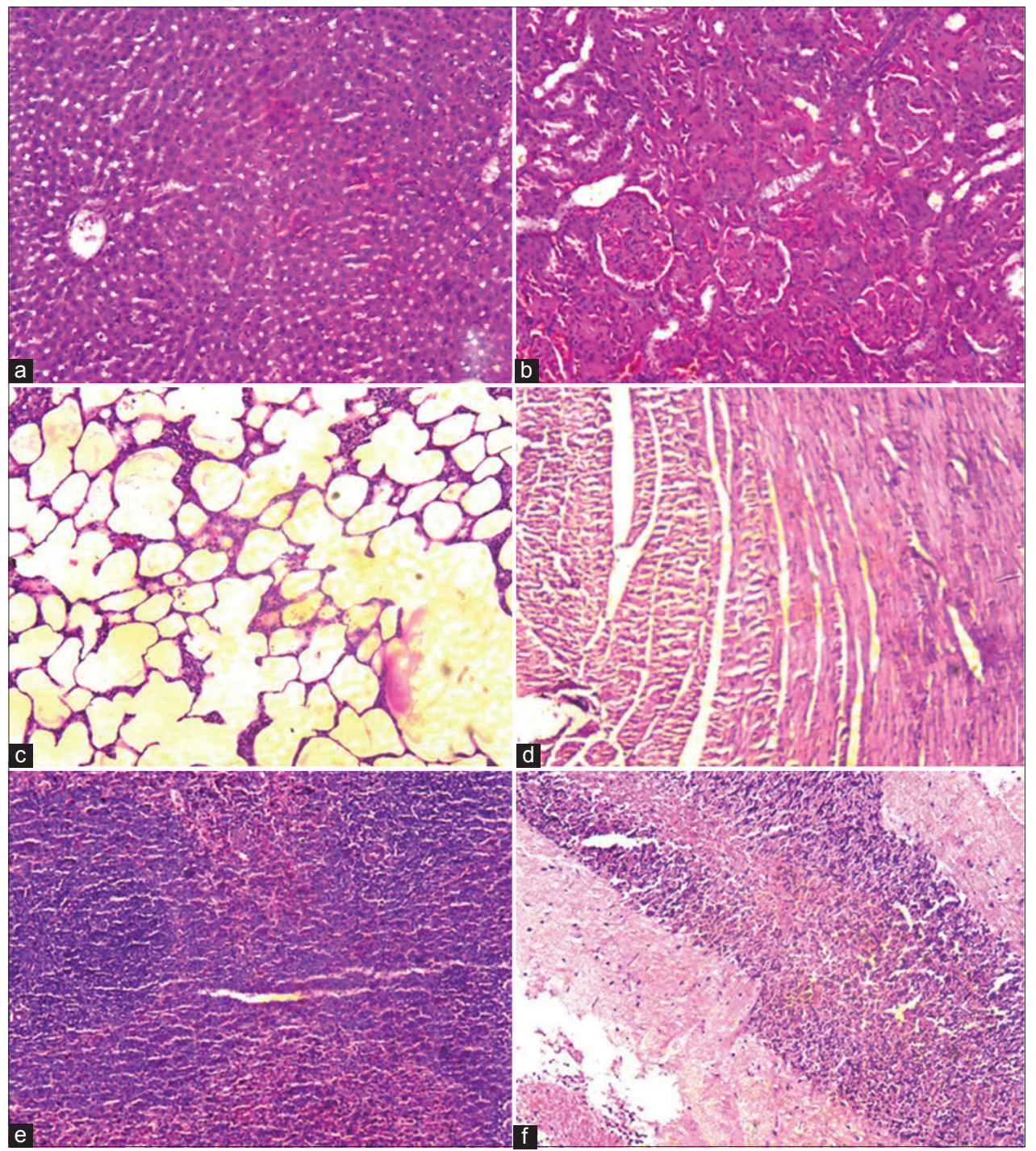

Fig. 2: Histopathological examination of liver (a), kidney (b), lung (c), heart (d), spleen (e), and brain (f) after I.V. administration of protodioscin rich extract $(1000 \mathrm{mg} / \mathrm{kg}$; I.V.)

Moreover, gross and pathological examinations of the internal organs after hematoxylin-eosin staining reveal no pathological abnormalities for rats in any group (Figs. 1 and 2). Based on biochemical and hematological findings as well as findings of the pathological analysis of the major organs, it was concluded that the PRE did not show significant toxicity in this experiment.
Fixed-dose procedure reveals the effect of PRE on animals, thus providing basic information for its toxicity studies. These results suggest that the PRE is not toxic with an acute exposure of $2000 \mathrm{mg} / \mathrm{kg} \mathrm{BW}$. However, the fixed-dose procedure has some limitations as the applicability of this dose to toxicity studies for other natural medicinal extracts still needs to be further investigated. 
Table 2: Hematological values for rats after oral and parenteral administration of protodioscin rich extract of Trigonella foenum-graecum L (Data are expressed as Mean \pm SEM)

\begin{tabular}{|c|c|c|c|c|c|}
\hline \multirow[t]{2}{*}{ Parameters } & \multirow[t]{2}{*}{ Normal range } & \multicolumn{2}{|c|}{ Oral administration } & \multicolumn{2}{|c|}{ Parenteral administration } \\
\hline & & Day 0 & Day 14 & Day 0 & Day 14 \\
\hline HB (g \%) & $13.6-17.4$ & $13.63 \pm 0.731$ & $14.5 \pm 0.328$ & $13.9 \pm 0.24$ & $14.6 \pm 0.481$ \\
\hline $\mathrm{RBC}\left(10^{6} / \mu \mathrm{L}\right)$ & $7.07-9.03$ & $7.7 \pm 0.231$ & $8.3 \pm 0.144$ & $7.8 \pm 0.53$ & $7.81 \pm 0.49$ \\
\hline $\mathrm{WBC}\left(10^{3} / \mu \mathrm{L}\right)$ & $1.13-7.49$ & $7.93 \pm 0.601$ & $5.83 \pm 0.906$ & $6 \pm 0.7$ & $5 \pm 1.1$ \\
\hline Platelets $\left(10^{3} / \mu \mathrm{L}\right)$ & $680-1200$ & $730 \pm 43.59$ & $731 \pm 79.41$ & $920 \pm 113.58$ & $893.3 \pm 150.19$ \\
\hline
\end{tabular}

SEM: Standard error mean, T. foenum-graecum: Trigonella foenum-graecum

\section{CONCLUSION}

Results demonstrate the safety of an acute oral and intravenous administration of PRE in rats. The $\mathrm{LD}_{50}$ could not be evaluated at the given dose. However, we conducted an acute toxicity test over a relatively short period ( 2 weeks) and not a complete chronic toxicity study with many doses that may demonstrate cumulative toxic effects. The subacute and long-term toxicity should be fully evaluated to determine the safety profile of PRE. Our results indicate that such additional toxicity testing is warranted.

\section{ACKNOWLEDGMENT}

The authors are thankful to the Charotar University of Science and Technology, Changa, Gujarat, India, for providing the facilities for completion of the project. Authors also thank Dr. Alpesh Patel, J \& J College of Science, Nadiad, for facilitating authentication of plant material and Dr. D. J. Ghodasara, Department of Veterinary Pathology, AAU, Anand, for the histopathological examination. Authors also thank Ms. Gopi Shah, for her support in biochemical analysis.

\section{REFERENCES}

1. Pour BM, Latha LY, Sasidharan S. Cytotoxicity and oral acute toxicity studies of Lantana camara leaf extract. Molecules 2011;16(5):3663-74.

2. Patil S, Jain G. Holistic approach of Trigonella foenum-graecum in phytochemistry and pharmacology. Curr Trends Technol Sci 2014;3(1):34

3. Basch E, Ulbricht C, Kuo G, Szapary P, Smith M. Therapeutic applications of fenugreek. Altern Med Rev J Clin Ther 2003;8(1):20-7.

4. Ulbricht C, Basch E, Burke D, Cheung L, Ernst E, Giese N, et al. Fenugreek (Trigonella foenum-graecum L. Leguminosae): An evidencebased systematic review by the natural standard research collaboration. J Herb Pharmacother 2007;7(3-4):143-77.

5. Jyothi D, Koland M. Formulation and evaluation of an herbal antiinflammatory gel containing trigonella foenum greacum seed extract. Int J Pharm Pharm Sci 2015;8(1):41-4.

6. Priyanka K, Singh R. A systematic review on Indian floral biodiversity as eminent reserves for alternative treatment strategy of diabetes mellitus. Int J Pharm Pharm Sci 2016;8(4):10-9.

7. EMA/HMPC/146220/2010, Assessment Report on Trigonella foenumgraecum L., Semen, Committee on Herbal Medicinal Products (HMPC), European Medicines Agency; 2010.

8. Department of AYUSH, Ministry of Health and Family Welfare, Govenment of India.

9. Herbal Medicines Compendium (HMC). U.S. Pharmacopeial Convention (USP). Rockville, MD: Herbal Medicines Compendium (HMC); 2013.
10. Adimoelja A, Adaikan PG. Protodioscin from herbal plant Tribulus terrestris L improves the male sexual functions, probably via DHEA. Int J Impot Res 1997;9(1):S1-70.

11. Gauthaman K, Adaikan PG, Prasad RN. Aphrodisiac properties of Tribulus terrestris extract (protodioscin) in normal and castrated rats. Life Sci 2002;71(12):1385-96.

12. Gauthaman K, Ganesan AP. The hormonal effects of Tribulus terrestris and its role in the management of male erectile dysfunction - An evaluation using primates, rabbit and rat. Phytomedicine 2008; 15(1-2):44-54.

13. Gauthaman K, Ganesan AP, Prasad RN. Sexual effects of puncturevine (Tribulus terrestris) extract (protodioscin): An evaluation using a rat model. J Altern Complement Med 2003;9(2):257-65.

14. Goswami SK, Pandre MK, Jamwal R, Dethe S, Agarwal A, Inamdar MN. Screening for Rho-kinase 2 inhibitory potential of Indian medicinal plants used in management of erectile dysfunction. J Ethnopharmacol 2012;144(3):483-9.

15. Iacono F, Prezioso D, Ruffo A, Di Lauro G, Romis L, Illiano E. Analyzing the efficacy of a new natural compound made of alga ecklonia bicyclis, Tribulus terrestris and Biovis in order to improve male sexual function. J Mens Health 2011;8(4):282-7.

16. Jamil M, Ansari J, Ali A, Ahamad J, Ali M, Tamboli E. Pharmacological scientific evidence for the promise of Tribulus terrestris. Int Res J Pharm 2012;3(5):403-6.

17. Kistanova E, Zlatev H, Karcheva V, Kolev A. Effect of plant Tribulus terrestris extract on reproductive performances of rams. Biotechnol Anim Husbandry 2005;21(1-2):55-63.

18. Singh S, Nair V, Gupta YK. Evaluation of the aphrodisiac activity of Tribulus terrestris L. In sexually sluggish male albino rats. J Pharmacol Pharmacother 2012;3(1):43-7.

19. Goel PK. Extract Obtained by a Commercially Viable Process for the Extraction of Furostanolic Saponins from Fenugreek Seeds, in Which One of the Compounds in the Extract is Protodioscin; 2012.

20. Hibasami H, Moteki H, Ishikawa K, Katsuzaki H, Imai K, Yoshioka K, et al. Protodioscin isolated from fenugreek (Trigonella foenumgraecum L.) induces cell death and morphological change indicative of apoptosis in leukemic cell line H-60, but not in gastric cancer cell line KATO III. Int J Mol Med 2003;11(1):23-6.

21. Variya K, Parmar V. A validated high-performance thin-layer chromatographic method for the quantitation of protodioscin in Trigonella foenum-graecum and its herbal formulations. J Planar Chromatogr Mod TLC 2015;28(6):458-65.

22. OECD. Acute Oral Toxic Class Method Guideline 423. Guideline for the Testing of Chemicals. Paris: Organization for Economics Cooperation and Development-OECD; 2000.

23. Clemo FA. Response to utility of clinical pathology reference ranges in preclinical safety studies. Toxicol Pathol 1997;25(6):650.

24. Lang P. Serum Chemistry Parameters for the Crl: $C D ® B R$ rat. Wilmington, MA: Charles River Laboratories, Inc.; 1993. 